\title{
Vitamin D receptor gene polymorphisms and idiopathic Parkinson disease: an Egyptian study
}

\author{
Ebtesam Mohamed Fahmy ${ }^{1}$, Mohamed Elsayed Elawady ${ }^{1}$, Sahar Sharaf ${ }^{2}$, Sarah Heneidy ${ }^{1}$ and \\ Rania Shehata Ismail $\left.\right|^{1 *}$
}

\begin{abstract}
Background: Accumulating data have suggested that vitamin D receptor (VDR) gene is a pretender gene for vulnerability to Parkinson disease (PD). This study aimed to assess the relationship of VDR gene polymorphisms (Fokl and Apal) with PD. Fifty patients suffering from PD and 50 age- and sex-matched healthy controls were included. Unified Parkinson Disease Rating Scale (UPDRS) was done to assess disease severity. Genetic testing for VDR gene single nucleotide polymorphisms (Fokl and Apal) was done using real time polymerase chain reaction (PCR) technique.
\end{abstract}

Results: Concerning frequency of genes and alleles for vitamin D receptor gene polymorphisms (Fokl and Apal), no statistically significant difference was found between PD patients and controls. AC genotype was associated with younger age and younger age at onset of disease compared to CC and AA genotypes of Apal gene polymorphisms. CC genotype was significantly positively correlated with fatigue and urine incontinence. VDR gene polymorphisms were not found to be independent predictors for severity of PD after adjustment for possible confounders.

Conclusion: VDR gene polymorphisms are related to the clinical manifestations rather than etiology or severity of idiopathic PD.

Keywords: Vitamin D receptor (VDR) gene polymorphisms, VDR-Apal SNP and VDR-FokI SNP gene polymorphisms, Idiopathic Parkinson disease (PD)

\section{Background}

Genetic studies on vitamin D receptor (VDR) polymorphisms have proposed contribution of VDR to several neurodegenerative disorders, including multiple sclerosis, Alzheimer disease, and Parkinson disease (PD) [1].

VDR gene is located on the long arm of chromosome 12 region. Genetic polymorphisms describe the interindividual, functionally silent differences in deoxy ribonucleic acid sequence that make each human genome unique. More than 60 VDR polymorphisms have been discovered. These polymorphisms are located in the

\footnotetext{
*Correspondence: raniashehata.neuro@yahoo.com

${ }^{1}$ Department of Neurology, Faculty of Medicine, Cairo University, Cairo, Egypt Full list of author information is available at the end of the article
}

promoter, in and around exons 2-9 and in the 3'untranslated region [2].

Vitamin D functions are modulated by VDR. It is activated upon binding to the active form of vitamin $\mathrm{D}$. It interacts with vitamin $\mathrm{D}$ response elements in the promoters of vitamin $\mathrm{D}$ target genes to regulate their expression. Remarkably, VDR is greatly expressed in dopaminergic neurons of the substantia nigra suggesting its role in the pathophysiology of PD [3].

Prior researchers have reported associations between severity and clinical manifestations of PD and VDR gene polymorphisms [4-9].

The present study aimed to study the relation between VDR gene polymorphisms (FokI and ApaI) and PD, and 
to examine their relation to clinical presentation and disease severity.

\section{Methods}

This is a case control study conducted on 50 Egyptian patients diagnosed as idiopathic Parkinson disease and 50 age- and sex-matched healthy controls, in the period from April 2017 to May 2018.

The study proposal was approved by the ethical committee of department of Neurology. The aim, procedures of the study, the data confidentiality was explained to every participant. Informed consent was obtained before patients were enrolled in the study.

Patients with PD diagnosed according to MDS clinical diagnostic criteria for Parkinson's disease, 2015 [10] were included. Their age ranged between 45 and 70 years old.

\section{Excluded from this study}

Patients with diseases that may disturb cognitive functions, such as, diabetes mellitus, renal, hepatic diseases, or thyroid dysfunction and patients with brain magnetic resonance imaging showing structural lesions.

Patients were submitted to comprehensive neurological evaluation. Unified Parkinson Disease Rating Scale (UPDRS) [11] was done to assess disease severity. VDR-ApaI SNP (rs7975232) and VDR-FokI SNP (rs 2228570) gene polymorphisms were tested using PCR. SNP genotyping of VDR gene was performed with the Type-it Fast SNP Probe Kit (Qiagen) according to the manufacturer's instructions using validated TaqMan * SNP genotyping primers and probe (Applied Biosystems, Foster City, CA, USA).

\section{Statistical analysis}

The collected data were coded, tabulated, and statistically analyzed using IBM SPSS statistics (Statistical Package for Social Sciences) software version 22.0, IBM Corp., Chicago, USA, 2013. Data was summarized using mean, standard deviation, median, minimum and maximum in quantitative data and using frequency (count) and relative frequency (percentage). Comparisons between quantitative variables were done using the nonparametric Kruskal-Wallis and Mann-Whitney tests. Chi square $(x 2)$ test was performed for categorical data. Exact test was used when the expected frequency is less than 5. Correlations between quantitative variables were done using Spearman correlation coefficient. Genotype and allele frequencies were compared between patients and control groups using logistic regression. Odds ratio (OR) with 95\% confidence intervals was calculated. Linear regression analysis was done to predict total severity scores using VDR polymorphisms. Logistic regression was done to detect independent predictors of severity. $P$ values less than 0.05 were considered as statistically significant.

\section{Result}

The age of patients ranged from 45 to 70 years with a mean of $60.8 \pm 5$ years whereas, the age of controls ranged from 46 to 68 years with a mean of $61.4 \pm 5.7$ years. The patients group included 34 males $(68 \%)$ and 16 females (32\%). The control group included 32 males (64\%) and 18 females (36\%). Patients and controls were matched regarding mean age and sex distribution $(p=$ $0.5,0.7$ respectively).

The age at onset of the disease ranged from 40 to 69 years with a mean $57.32 \pm 6.40$ years, while disease duration ranged from 1 to 10 years with a mean $3.42 \pm 2.35$ years. Six patients $(12 \%)$ had positive family history of PD.

Forty patients $(80 \%)$ presented with tremor dominant phenotype while, 10 patients $(20 \%)$ presented with postural instability gait difficulty phenotype.

Constipation was found in 28 (56\%) patients, memory impairment in $15(30 \%)$ patients, visual problems in 13 (26\%) patients, sleep behavior disorder (REM) in 12 (24\%) patients, depression in $9(18 \%)$ patients, erectile dysfunction in $3(6 \%)$ patients, insomnia in $3(6 \%)$ patients, and fatigue in $1(2 \%)$ patient.

Scores of UPDRS were as follows: mentation, behavior, and mood section UPDRS score ranged from 0 to 7 with median 1, activities of daily living (ADL) section score ranged from 1 to 33 with median 19 and, motor section score ranged from 12 to 47 with median 28 .

According to $\mathrm{H}$ and $\mathrm{Y}$ staging, 20 patients $(40 \%)$ had stage 1,11 patients $(22 \%)$ had stage $1.5,9$ patients (18\%) had stage 2, 4 patients $(8 \%)$ had stage $2.5,4$ patients (8\%) had stage 3 , and 2 patients (4\%) had stage 4 .

For statistical reasons, we added the AA and AG genotypes in FokI polymorphism as AA genotype was found only in one patient. No statistically significant difference was found between the studied groups concerning the distribution of VDR genotypes and alleles $(p>0.05)$ (Table 1).

In SNP FokI, no statistically significant difference was detected between distribution of different genotypes AA, AG, and AG ( $P$ value $=0.480)$. While SNP ApaI showed a statistically significant difference between distribution of CC, AC, and AA genotypes $(P$ value $=0.002)$. Pairwise comparison revealed that $\mathrm{AC}$ was significantly present compared to $\mathrm{CC}$ and AA $(p<0.001)$ and AA was significantly present compared to $C C(P=0.008)$. This indicates that among PD patients, AC genotype was the most common and the $\mathrm{CC}$ was the least frequent genotype (Table 2).

There is a tendency towards significant preponderance of male sex in FokI GG genotype $(p=0.068)$. A 
Table 1 VDR gene polymorphisms distribution in the studied groups

\begin{tabular}{|c|c|c|c|c|c|c|}
\hline \multirow{2}{*}{\multicolumn{2}{|c|}{$\begin{array}{l}\text { VDR gene } \\
\text { polymorphisms }\end{array}$}} & \multicolumn{2}{|c|}{ Patients } & \multicolumn{2}{|c|}{ Controls } & \multirow[t]{2}{*}{$P$ value } \\
\hline & & Count & $\%$ & Count & $\%$ & \\
\hline \multirow[t]{4}{*}{ rs2228570 (Fokl) } & $A A+A G$ & 22 & 44 & 25 & 50 & 0.548 \\
\hline & GG & 28 & 56 & 25 & 50 & 0.51 \\
\hline & Allele A & 23 & 23 & 27 & 27 & 0.51 \\
\hline & Allele G & 77 & 77 & 73 & 73 & 1 \\
\hline \multirow[t]{5}{*}{ rs7975232 (Apal) } & $\mathrm{CC}$ & 8 & 16 & 8 & 16 & 1 \\
\hline & $A C$ & 28 & 56 & 21 & 42 & 0.161 \\
\hline & $\mathrm{AA}$ & 14 & 28 & 21 & 42 & 0.142 \\
\hline & Allele C & 44 & 44 & 37 & 37 & 0.314 \\
\hline & Allele A & 56 & 56 & 63 & 63 & 0.314 \\
\hline
\end{tabular}

VDR vitamin D receptor

statistically significant difference was found in VDR gene rs7975232 (ApaI) polymorphisms regarding mean age and age at onset of disease ( $p=0.005$ and 0.012 , respectively). Post hoc test revealed a statistically significant difference between AA and $\mathrm{AC}$ in the mean age and age at onset of disease $(P=0.004$ and 0.009 , respectively). AC genotype was associated with younger age and younger age at onset of disease compared to $\mathrm{CC}$ and AA genotypes (Figs. 1 and 2).

However, there was no statistically significant difference between ApaI polymorphisms in the mean duration of disease. Also, there was no statistically significant difference in VDR gene rs2228570 (FokI) polymorphisms regarding mean age, age at onset of disease, or duration of disease ( $P=0.179,0.170$, and 0.578 , respectively).

Regarding VDR gene ApaI polymorphisms, CC genotype was significantly positively correlated with fatigue and urine incontinence $(r=0.32, P=0.02)$. However, there was no statistically significant difference between FokI and ApaI VDR gene polymorphisms regarding starting motor symptom.

VDR gene FokI and ApaI polymorphisms were not significantly correlated with scores of UPDRS or $\mathrm{H}$ and $\mathrm{Y}$ staging $(p>0.05)$.

Linear regression analysis was done between UPDRS-I scores, activity of daily living, and motor examination as

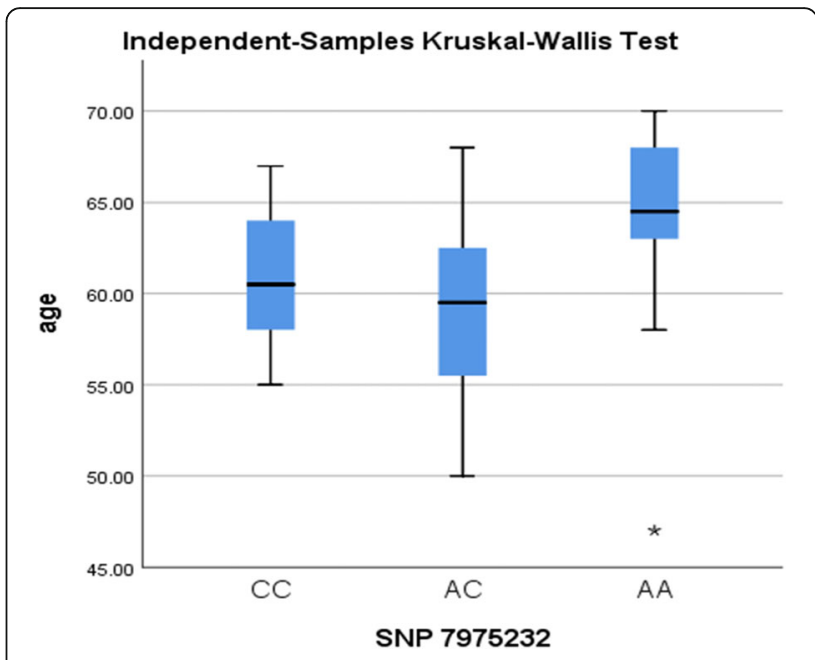

Fig. 1 Relation between VDR gene Apal polymorphism and age of patients. VDR: vitamin $\mathrm{D}$ receptor

dependent factors and VDR polymorphisms as independent factor. Logistic regression analysis was also done between modified $\mathrm{H}$ and $\mathrm{Y}$ scale as dependent factor and VDR polymorphisms as independent factor. We found that $P$ value was not significant after adjustment for age, sex, age at onset of disease, and disease duration. This points to that VDR gene polymorphisms were not independent predictors for UPDRS scores or $\mathrm{H}$ and $\mathrm{Y}$ staging (Tables 3 and 4).

\section{Discussion}

In the current study, no statistically significant difference of genotypes or allele occurrence for VDR gene polymorphism (FokI and ApaI) between PD patients and healthy controls. This was in agreement with Petersen and colleagues. (2014) [12], who found no statistical significant difference between PD patients and controls regarding genotypes or allele frequency for VDR gene polymorphism ApaI. On the contrary, a Turkish study by Gezen and colleagues (2017) [13] reported that in ApaI polymorphism, allele $\mathrm{C}$ was expressively more in PD patients than controls and significantly increases the risk of developing PD irrespective of age and age at onset. Also, a previous study done on a Chinese cohort

Table 2 VDR polymorphisms distribution in the patients group

\begin{tabular}{lllll}
\hline VDR gene polymorphisms & & \multicolumn{2}{l}{ Patients } & \multicolumn{1}{l}{$\boldsymbol{P}$ value } \\
\cline { 2 - 4 } & & Count & $\%$ & \\
\hline rs2228570 (Fokl) & AA+AG & 22 & 44 & 0.480 \\
& GG & 28 & 56 & \\
rs7975232 (Apal) & CC & 8 & 16 & $0.002^{* *}$ \\
& AC & 28 & 56 & Pairwise comparison: \\
& AA & 14 & 28 & CC versus AC $<0.001^{* *}$ CC versus AA $0.008^{* *}$ AA versus AC $<0.001^{* *}$ \\
\end{tabular}

**Highly significant $(P$ value $<0.001) ; V D R$ vitamin $D$ receptor 


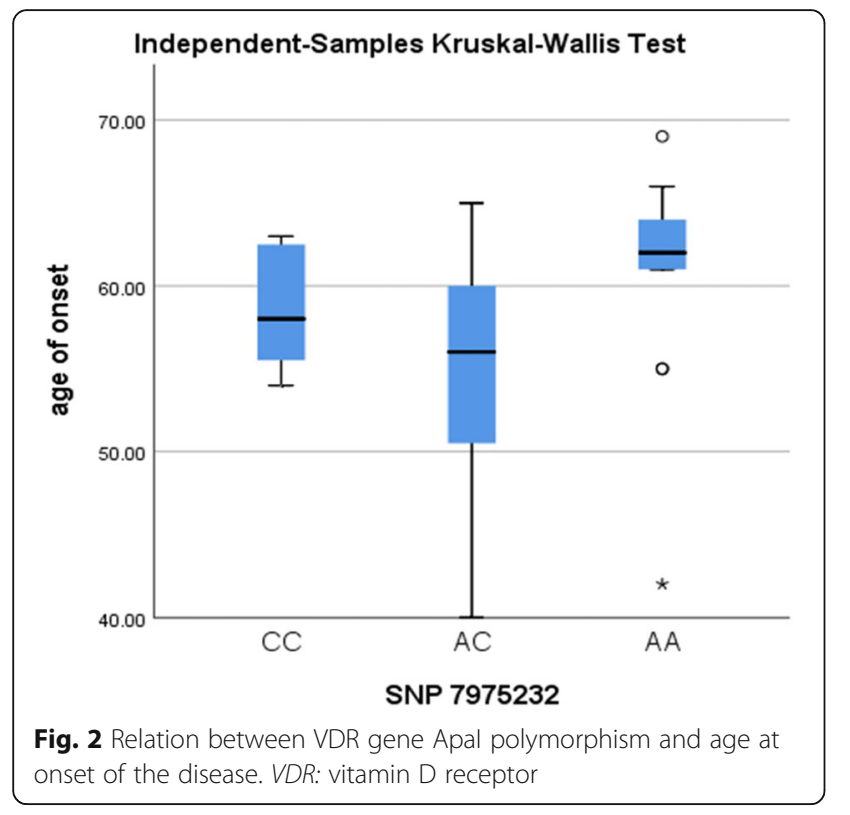

revealed that the frequency of FokI CC + CT genotypes was higher in PD patients compared to controls [14]. Another study done on Hungarian by Torok and colleagues (2013) [6] found that VDR FokI CC + CT genotypes were higher among $\mathrm{PD}$ patients compared to controls. The controversy between studies may be attributed to differences in sample size and ethnic backgrounds, which may have effect on the genetic map.

The present study revealed that ApaI AC genotype was associated with younger age and younger age at onset of disease compared to CC and AA genotypes. The neuroprotective theory of VDR gene in the pathophysiology of PD can provide some explanation to this finding. The younger age at disease onset in patients with AC genotype could lead to dopaminergic neuronal damage due to defective process of neuroprotection. The nigral dopaminergic neurons appear to be the first suffer from neuro-inflammation and decreased neuroprotection [14]. Also, Han and colleagues (2012) [14] found significant difference in FokI genotype distribution between early onset PD patients and healthy controls, as
Table 4 Logistic regression analysis model between modified H\&Y scale and VDR polymorphisms

\begin{tabular}{llllll}
\hline & & $P$ value & OR & \multicolumn{2}{l}{$\mathbf{9 5 \%} \mathrm{Cl}$} \\
\cline { 5 - 6 } & & & & Lower & Upper \\
\hline $\begin{array}{llllll}\text { Modified H\&Y } \\
\text { scale }\end{array}$ & rs2228570 Fokl & 0.653 & 1.589 & 0.210 & 12.017 \\
& $\begin{array}{l}\text { rs7975232 } \\
\text { Apal }\end{array}$ & 0.665 & 1.705 & 0.153 & 19.043 \\
& & & & & \\
\hline
\end{tabular}

$O R$ odds ratio, $\mathrm{Cl}$ confidence interval, $H \& Y$ scale Hoehn and Yahr staging

FokI CT + CC genotypes raised risk of early onset PD compared to FokI TT genotype. On contradistinction to this finding, Torok and colleagues (2013) [8] showed no significant association between VDR gene polymorphism FokI and ApaI and the age at onset of PD. The discrepancies between these studies could be explained by differences in ethnic backgrounds and difficulties in determining the actual age at onset of the disease

In the current study, a significant positive correlation was detected between fatigue and urine incontinence and CC genotype of VDR ApaI polymorphisms. To the best of our knowledge, no previous studies correlated VDR gene polymorphisms distribution and non-motor symptoms of PD. However, this study revealed no association between VDR gene polymorphisms and motor symptoms of PD, a finding which agreed with Gezen and colleagues (2017) [6] who reported no association between motor symptoms of PD patients and ApaI and FokI genotypes.

The present study showed no relation between severity of PD assessed by UPDRS and $\mathrm{H}$ and $\mathrm{Y}$ staging and VDR gene polymorphisms after adjustment for possible confounders. On the contrary, Suzuki and colleagues (2012) [15] reported that FokI CC genotype was significantly associated with lower $\mathrm{H}$ and $\mathrm{Y}$ stages. The discrepancy may be related to the inclusion of small sample size in this work compared to that of Suzuki and colleagues (137 patients). Moreover, most of our patients had $\mathrm{H}$ and $\mathrm{Y}$ staging less than 3.

\section{Conclusion}

It could be concluded that VDR FokI and ApaI genotypes are related to clinical presentations rather than

Table 3 Regression analysis model for scores of UPDRS and VDR Fokl and Apal polymorphisms

\begin{tabular}{|c|c|c|c|c|c|c|c|c|}
\hline \multirow[t]{2}{*}{ Model } & & \multicolumn{2}{|c|}{ Unstandardized coefficient } & \multirow{2}{*}{$\begin{array}{l}\text { Standardized } \\
\text { coefficient }\end{array}$} & \multirow[t]{2}{*}{$T$} & \multirow[t]{2}{*}{$P$ value } & \multirow{2}{*}{\multicolumn{2}{|c|}{$\begin{array}{l}95 \% \text { confidence } \\
\text { interval for B }\end{array}$}} \\
\hline & & $B$ & Std. error & & & & & \\
\hline Total mentation score & Fokl & $-0.294-$ & 0.290 & $-0.156-$ & -1.016 & 0.315 & -0.879 & 0.290 \\
\hline Total ADL score & & $-0.275-$ & 1.190 & $-0.033-$ & -0.231 & 0.818 & -2.674 & 2.124 \\
\hline Total motor score & & $-1.064-$ & 1.301 & $-0.109-$ & -0.818 & 0.418 & -3.685 & 1.558 \\
\hline Total mentation score & Apal & $-0.002-$ & 0.334 & $-0.001-$ & -0.006 & 0.995 & -0.675 & 0.671 \\
\hline Total ADL score & & 0.527 & 1.354 & 0.058 & 0.389 & 0.699 & -2.202 & 3.255 \\
\hline Total motor score & & -0.106 & 1.492 & $-0.010-$ & -0.071 & 0.944 & -3.113 & 2.900 \\
\hline
\end{tabular}


etiology or severity of idiopathic PD. Future studies including larger sample size and different stages of PD are recommended for more clarification of the potential role of VDR polymorphisms in the pathogenesis and progression of PD, which may suggest new management strategies to slow the progression of the disease.

\section{Abbreviations}

ADL: Activities of daily living; $H$ and $Y$ : Hoehn and Yahr staging:

PCR: Polymerase chain reaction; PD: Parkinson disease; UPDRS: Unified

Parkinson Disease Rating Scale; VDR: Vitamin D receptor

\section{Acknowledgements}

The authors acknowledge subjects for their participation and cooperation in this study.

\section{Authors' contributions}

EMF: research idea and conception, data acquisition, data analysis and interpretation, and manuscript writing and reviewing. MEE: research idea, data acquisition, data analysis, and interpretation. SS: performing and reviewing the laboratory workup. SH: data acquisition, data analysis, and interpretation. RSI: data acquisition, data analysis and data interpretation, and manuscript writing and reviewing. All authors have read and approved the manuscript.

\section{Funding}

This research received no specific grant from any funding agency in the public, commercial, or not-for-profit sectors.

\section{Availability of data and materials}

The datasets generated and/or analyzed during the current study are not publicly available due to current Cairo University regulations and Egyptian legislation but are available from the corresponding author on reasonable request and after institutional approval.

\section{Declarations}

\section{Ethics approval and consent to participate}

The aim and procedures of the study were explained to every participant and an informed written consent was obtained from all participants before being enrolled in the study. The study was approved by the ethical committee of the Neurology Department, Cairo University Hospitals (4/3/ 2017)

\section{Consent for publication}

Not applicable.

\section{Competing interests}

The authors declare that they have no competing interests.

\section{Author details}

'Department of Neurology, Faculty of Medicine, Cairo University, Cairo, Egypt. ${ }^{2}$ Department of Clinical Pathology, Faculty of Medicine, Cairo University, Cairo, Egypt.

Received: 25 February 2021 Accepted: 14 July 2021

Published online: 27 July 2021

\section{References}

1. Morello M, Pieri M, Zenobi R, Talamo A, Stephan D, Landel V, et al. The influence of vitamin $D$ on neurodegeneration and neurological disorders: a rationale for its physio-pathological actions. Current pharmaceutical design. 2020;26(21):2475-91. https://doi.org/10.2174/1381612826666200316145725.

2. Taymans SE, Pack S, Pak E, Orban Z, Barsony J, Zhuang Z, et al. The Human vitamin $D$ receptor gene (VDR) is localized to region 12 cen-q12 by fluorescent in situ hybridization and radiation hybrid mapping: genetic and physical VDR map. J Bone Miner Res. 1999;14(7):1163-6. https://doi.org/1 0.1359/jbmr.1999.14.7.1163.
3. Niu MY, Wang L, Xie AM. Apal, Bsml, Fokl, and Taql polymorphisms in the vitamin D receptor gene and Parkinson's disease. Chin Med J. 2015;128(13): 1809-14. https://doi.org/10.4103/0366-6999.159358.

4. Butler MW, Burt A, Edwards TL, Zuchner S, Scott WK, Martin ER, et al. Vitamin D receptor gene as a candidate gene for Parkinson disease. Ann Hum Genet. 2011;75(2):201-10. https://doi.org/10.1111/j.1469-1809.2010. 00631.x.

5. Lv Z, Tang B, Sun Q, Yan X, Guo J. Association study between vitamin d receptor gene polymorphisms and patients with Parkinson disease in Chinese Han population. Int J Neurosci. 2012;123(1):60-4. https://doi.org/1 0.3109/00207454.2012.726669.

6. Török R, Török N, Szalardy L, Plangar I, Szolnoki Z, Somogyvari F, et al. Association of vitamin D receptor gene polymorphisms and Parkinson's disease in Hungarians. Neurosci Lett. 2013;551:70-4. https://doi.org/10.1016/ j.neulet.2013.07.014.

7. Lin $\mathrm{CH}$, Chen $\mathrm{KH}$, Chen ML, Lin HI, Wu RM. Vitamin D receptor genetic variants and Parkinson's disease in a Taiwanese population. Neurobiol Aging. 2014;35(5):1212-e11.

8. Lv L, Tan X, Peng X, Bai R, Xiao Q, Zou T, et al. The relationships of vitamin $D$, vitamin $D$ receptor gene polymorphisms, and vitamin D supplementation with Parkinson's disease. Transl Neurodegener. 2020;9(1): $1-3$.

9. Gao J, Teng J, Liu Z, Cai M, Xie A. Association between vitamin D receptor polymorphisms and susceptibility to Parkinson's disease: an updated metaanalysis. Neurosci Lett. 2020;720:134778. https://doi.org/10.1016/j.neulet.202 0.134778.

10. Fahn S. Members of the UPDRS development committee. Unified Parkinson's disease rating scale. Recent Dev Parkinson's Dis. 1987;2:293-304.

11. Goetz CG, Tilley BC, Shaftman SR, Stebbins GT, Fahn S, Martinez-Martin P, et al. Movement Disorder Society- sponsored revision of the Unified Parkinson's Disease Rating Scale (MDS-UPDRS): scale presentation and clinimetric testing results. Mov Disord. 2008;23(15):2129-70.

12. Petersen MS, Bech S, Christiansen DH, Schmedes AV, Halling J. The role of vitamin D levels and vitamin D receptor polymorphism on Parkinson's disease in the Faroe Islands. Neurosci Lett. 2014;561:74-9. https://doi.org/1 0.1016/j.neulet.2013.12.053

13. Gezen-Ak D, Alaylıoğlu M, Genç G, Gündüz A, Candaş E, Bilgiç B, et al. GC and VDR SNPs and vitamin D levels in Parkinson's disease: the relevance to clinical features. Neuromolecular Med. 2017;19(1):24-40. https://doi.org/10.1 007/s12017-016-8415-9.

14. Han $X$, Xue L, Li Y, Chen B, Xie A. Vitamin D receptor gene polymorphism and its association with Parkinson's disease in Chinese Han population. Neurosci Lett. 2012;525(1):29-33. https://doi.org/10.1016/j.neulet.2012.07.033.

15. Suzuki M, Yoshioka M, Hashimoto M, Murakami M, Kawasaki K, Noya M, et al. 25hydroxyvitamin $D$, vitamin $D$ receptor gene polymorphisms, and severity of Parkinson's disease. Mov Disord. 2012;27(2):264-71. https://doi. org/10.1002/mds.24016.

\section{Publisher's Note}

Springer Nature remains neutral with regard to jurisdictional claims in published maps and institutional affiliations.

\section{Submit your manuscript to a SpringerOpen ${ }^{\circ}$ journal and benefit from:}

- Convenient online submission

- Rigorous peer review

- Open access: articles freely available online

High visibility within the field

- Retaining the copyright to your article

Submit your next manuscript at $>$ springeropen.com 